\title{
Effects of hyperleptinemia in rat saliva composition, histology and ultrastructure of the major salivary glands
}

\author{
Elsa Lamy ${ }^{\mathrm{a}, *}$, Sandra Neves ${ }^{\mathrm{b}}$, Joana Ferreira ${ }^{\mathrm{b}}$, Lénia Rodrigues ${ }^{\mathrm{a}}$, Gonçalo da Costa ${ }^{\mathrm{c}}$, \\ Orlando Lopes ${ }^{\mathrm{a}, \mathrm{e}}$, Francisco Amado ${ }^{\mathrm{g}, \mathrm{h}}$, Fernando Capela e Silva ${ }^{\mathrm{a}, \mathrm{e}}$ \\ a Instituto de Ciências Agrárias e Ambientais Mediterrânicas (ICAAM), Universidade de Évora, 7002-554 Évora, Portugal \\ b Departamento de Química, Escola de Ciências e Tecnologia, Universidade de Évora, 7002-554 Évora, Portugal \\ ' Centro de Química e Bioquímica, Faculdade de Ciências, Universidade de Lisboa, 1749-016 Lisboa, Portugal \\ ${ }^{\mathrm{d}}$ Departamento de Medicina Veterinária, Escola de Ciências e Tecnologia, Universidade de Évora, 7002-554 Évora, Portugal \\ e Departamento de Biologia, Escola de Ciências e Tecnologia, Universidade de Évora, 7002-554 Évora, Portugal \\ ${ }^{\mathrm{f}}$ Instituto de Ciências da Terra (ICT), Universidade de Évora, 7002-554 Évora, Portugal \\ ${ }^{\mathrm{g}}$ Departamento de Química, Universidade de Aveiro, 3810 Aveiro, Portugal \\ ${ }^{\mathrm{h}}$ Química Orgânica, Produtos Naturais e Agroalimentares (QOPNA), Universidade de Aveiro, 3810 Aveiro, Portugal
} Carlos Cordeiro $^{\mathrm{c}}$, Luísa Fialho ${ }^{\mathrm{d}}$, Mónica Lima ${ }^{\mathrm{e}}$, Ana Rodrigues Costa ${ }^{\mathrm{b}, \mathrm{f}}$, Célia Miguel Antunes ${ }^{\mathrm{b}, \mathrm{f}}$,

\section{A R T I C L E I N F O}

\section{Keywords:}

Salivary proteomics

Leptin

Salivary glands

Amylase

\begin{abstract}
A B S T R A C T
Objective: To study the effect of the satiety hormone, leptin, in saliva proteome and salivary gland histology and ultrastructure.

Design: Increases in blood leptin levels were induced through mini-pump infusion in male Wistar rats, during a period of 7 days. Saliva was collected before and at the end of the experimental period, for proteomic analysis, and major salivary glands were collected, at the end, for biochemical, histological and ultrastructural analysis. Results: Immunohistochemistry revealed the presence of leptin receptors in major salivary glands. Salivary amylase levels and enzymatic activity were decreased in saliva, whereas the enzymatic activity of this protein was increased in the cytosol of parotid gland cells. Transmission electron microscopy allowed the observation of high number of electron-dense granules in cytosol of parotid acinar cells, from leptin treated animals. Conclusions: Increased levels of plasmatic leptin result in changes in saliva composition and salivary glands function. To our knowledge, this is the first study providing evidences for a potential role of leptin in salivary gland secretion and saliva composition. An understanding of how appetite/satiety factors influence saliva composition and how this composition influences food processing in mouth may be relevant in understanding ingestivebehaviour.
\end{abstract}

\section{Introduction}

Leptin is a hormone mainly produced by adipose tissue that influences energy balance, inducing satiety and energy expenditure, as extensively reviewed (e.g. Allison \& Myers, 2014; Elmquist, Elias, \& Saper, 1999; Zhou \& Rui, 2013). The involvement of leptin in food intake and energetic balance results mainly from its action in the hypothalamic appetite/satiety centres, with an impact on ingestive and digestive processes. The observation that the functional form of leptin receptor $(\mathrm{ObRb})$ is present in peripheral tissues including liver, heart, kidneys, lungs, small intestine, testes, ovaries, spleen, pancreas, salivary glands and adipose tissue, among others (Schulz \& Widmaier, 2007), also indicates that leptin has a possible role in energy regulation and metabolism at a peripheral level.

The mouth is the first door for the entry of food in digestive tract, being the place where taste and aroma perception takes place and where digestion is initiated. The presence of the functional form of leptin receptor in taste buds has been observed (Shigemura, Miura, Kusakabe, Hino, \& Ninomiya, 2003) and the effects of leptin on oral food perception have been reported: sweet taste sensitivity has been suggested to decrease with increasing levels of leptin (Meredith, Corcoran, \& Roper, 2015), although this is a non-consensual issue, with studies observing no decreases in sweet responsiveness in response to increased levels of this hormone (Glendinning et al., 2015).

Saliva, a fluid resultant from the secretion of three pairs of major (parotid, submandibular and sublingual) and numerous minor salivary

\footnotetext{
* Corresponding author.

E-mail address: ecsl@uevora.pt (E. Lamy).
} 